Indian J. Genet., 75(2): 208-214 (2015)

DOI: $10.5958 / 0975-6906.2015 .00032 .2$

\title{
Mechanism of water-logging tolerance in pigeonpea
}

\author{
A. J. Hingane ${ }^{\star}$, K. B. Saxena, S. B. Patil, R. Sultana ${ }^{1}$, S. Srikanth, N. Mallikarjuna, R. Vijaykumar and \\ C. V. Sameer Kumar
}

International Crops Research Institute for the Semi-Arid Tropics, Patancheru 502 324, Andhra Pradesh; ${ }^{1}$ Bihar Agricultural University, Bhagalpur, Bihar

(Received: November 2014; Revised: March 2015; Accepted: April 2015)

\begin{abstract}
A study was undertaken to identify the morphophysiological traits associated with water-logging tolerance in pigeonpea [Cajanus cajan L. (Millsp.)].The formation of aerenchyma cells, lenticels, and adventitious roots in the tolerant genotypes were found to be associated with waterlogging tolerance in pigeonpea. The tolerant genotypes, namely, ICP 5028, ICPH 2431, ICPL 87119, ICPH 2740, ICPL 149, ICPL 20241, and MAL15, exhibited varying responses to hypoxic conditions. Formation of aerenchymatous cells was common in all the water-logging tolerant genotypes. Besides this, five tolerant genotypes (ICP 5028, ICPH 2431, ICPL 87119, ICPH 2740 and MAL 15) developed lenticels, while ICPL 149 and ICPL 20241 formed prominent adventitious roots. None of these traits was present in the susceptible genotypes. These traits developed only when exposed to water-logging stress and facilitated oxygen supply from stem to roots helping in respiration of the suffering plants. Potential breeding strategies to develop pigeonpea genotypes with enhanced levels of waterlogging tolerance are discussed.
\end{abstract}

Key words: Pigeonpea, water logging, aerenchyma, lenticels, adventitious roots, tolerance

\section{Introduction}

Pigeonpea [Cajanus cajan (L.) Millsp.] is an important pulse crop of India, sown at the onset of rainy season on $4.2 \mathrm{~m}$ ha with a production of $2.53 \mathrm{~m} \mathrm{t}$. The mean productivity of pigeonpea, is unacceptably low 740 $\mathrm{kg} / \mathrm{ha}$ (FAO 2010) and it has remained stagnant for almost five decades. Besides low yield potential of the crop, low crop productivity is also a consequence of various biotic and abiotic stresses which adversely affect the physiology of yield formation in a given environment. Being a rainy season crop, pigeonpea is invariably exposed to intermittent water-logging conditions for different durations from germination to early vegetative growth stages. According to Singh et al. (1986), germination and early vegetative stages of pigeonpea are more sensitive to water-logging stress as compared to mature plants. As per the earlier reports of Ponnamperuma (1984), the principal cause of damage to plants under flooded conditions is inadequate supply of oxygen from shoots to the submerged tissues, particularly roots; and as a consequence, the functioning and survival of root tissues is threatened. Hence, it is postulated that any plant mechanism that can restore the oxygen supply to the flooded tissues will help in the survival of the plants. Armstrong (1979) demonstrated that the formation of aerenchyma cells, hypertrophied lenticels, and adventitious roots facilitate gas diffusion to the roots and thus contribute directly to survival of the plants under water-logging. The present study was aimed to get some insight on the mechanisms of waterlogging tolerance in pigeonpea, using water-logging tolerant and susceptible pigeonpea genotypes identified earlier by Sultana et al. (2012).

\section{Materials and methods}

Initially, during 2010-12, forty nine pigeonpea genotypes differing in maturity, seed colour and origin were screened under natural field conditions to identify tolerant source to water-logging stress. The field trial was conducted at ICRISAT, Patancheru, Telangana, $\left(17^{\circ} 32^{\prime} \mathrm{N}, 78^{\circ} 16^{\prime} \mathrm{E}, 545 \mathrm{~m}\right.$ a.s.l.) with four replications using a $7 \times 7$ lattice design in deep Vertisols on a flatbed rice field with no drainage. Plants were allowed to grow normally up to 35 days after sowing and then stress treatment was imposed by submerging the field in such a way that, at least $20 \mathrm{~mm}$ plant height was

*Corresponding author's e-mail: h.anupama@cgiar.org

Published by the Indian Society of Genetics \& Plant Breeding, F2, First Floor, NASC Complex, PB\#11312, IARI, New Delhi 110012 Online management by indianjournals.com 
under water for continuous eight days. After draining the water the number of surviving plants was counted and rate of survival was estimated with reference to the number of plants present before the treatment (Sultana et al. 2012). Thus, based on survival data for two years, seven water-logging tolerant (ICPH 2740, MAL15, ICPL 87119, ICPH 2431, ICP 5028, ICPL 20241, and ICPL 149,) and seven sensitive (ICP7035, ICP 8755, ICPL 87091, ICPL 87051, ICP 8863, ICPL 2376 and ICPL 227) genotypes were identified to study the physiological and anatomical parameters associated with water-logging tolerance. The present experiment was conducted in a glass house using plastic pots of $25 \mathrm{~cm}$ diameter. Each pot was filled with $10 \mathrm{~kg}$ of soil mixture containing Vertisols and farmyard manure in the ratio of 50:1 (v/v). For each genotype, eight pots were prepared (four for imposing stress treatment and four as control). The experiment was sown on November 3, 2012, with four seeds/pot, at 2-3 cm soil depth in a completely randomized block design. The soil moisture in the pots was maintained at 60 to $90 \%$ field capacity during the entire period of the experiment. The average temperature and relative humidity in the glasshouse were maintained at $32 \pm 2^{\circ} \mathrm{C}$ and $60 \%$, respectively. Seedlings in the pots were thinned to three per pot at 21 days after sowing and allowed to grow normally till 35 days. Water-logging treatment was imposed on $36^{\text {th }}$ day for eight days by maintaining uniform water level of $20 \mathrm{~mm}$ above the soil surface of the pots, whereas the control pots were maintained at close to field capacity. On day nine, the plants were relieved from water logging by draining excess water and allowing them to recover. Observations on number of live plants before and after water-logging were recorded to estimate percent plant survival. In addition, visual scores on plant senescence were also recorded on day 8, 16, and 24 after draining the water. Scoring for senescence was done using a 1 to 3 scale ( $1=$ no senescence, $2=$ moderate senescence and 3 = complete senescence) (Tokale and Mcdavid 1995; Zaidi et al. 2007). Visual observations were also recorded on the formation of adventitious roots and lenticels on each plant. To study the formation of aerenchyma cells three samples from the region of root-shoot junction of each genotype were taken from the flooded and the control pots on day 8, 16, and 24 after the water-logging treatment. Sample preparation for the microscopic study was done according to Gunawardena et al. (2001a, 2001b) and each slide was examined for the presence of aerenchyma cells under Carl Zeiss compound microscope.

\section{Results and discussion}

Water-logging is a widespread production constraint for pigeonpea, especially in high rainfall and poorly drained habitats. The significant biological consequence of water-logging is the deficiency (hypoxia) or complete absence (anoxia) of oxygen in the soil; this sets anerobic conditions and restricts the plant growth and development, and consequently the seed yield. The tolerant pigeonpea genotypes can adapt to transient water-logging by inducing certain built-in mechanisms, rapidly assisting plants in their struggle for survival under excess water stress conditions. The common adaptation features of plants to water-logging condition are development of numerous adventitious roots and lenticels with the formation of aerenchymatous cells (Shimamura et al. 2010).

Observations on plant survival and senescence were recorded (Table 1) before and after imposing water-logging stress. In general all the seven tolerant genotypes confirmed the results of Sultana et al. (2012) and exhibited tolerant reaction. Among these ICP 5028, ICPL 20241 and MAL15 were the best with 100\% survival and with a smaller senescence score between 1.7 and 2. Among the sensitive types, ICP 7035 and ICP8863 were found most sensitive to with no survival recording a high senescence score of 3 . The other tolerant genotypes were ICPH 2740 (83\% survival), ICPH 2431 (67\% survival), ICPL 87119 (67\% survival), ICPL 149 (67\% survival) and ICPL 227(53\% survival) confirmed their tolerance to water-logging stress. An attempt was also made to correlate water-logging response of the genotypes with their maturity and seed colour (Table 2). In general, the late maturing genotypes showed higher tolerance to water-logging stress than early maturing types. Also, most dark seed coat colour genotypes tolerated seedling water-logging stress quite well. Greater tolerance in the late maturing group is likely to be related to the availability of more time for further recovery from the sub-lethal water-logging stress (Khare et al. 2002). Besides this, Hou and Thsenge (1991) in soybean and Khare et al. (2002) in pigeonpea also correlated flooding tolerance of genotypes with their dark seed coat colour; which was attributed to the presence of greater amounts of tannins in the genotypes. However, it is yet to be established with greater evidence. Genotypes like ICP 7035 produces tannins in the seed coat but is highly susceptible to water-logging. According to Marshner (1995) the genotypes which do not adapt to water- 
Table 1. Plant stand, survival rate and senescence scores of genotypes evaluated for water-logging tolerance

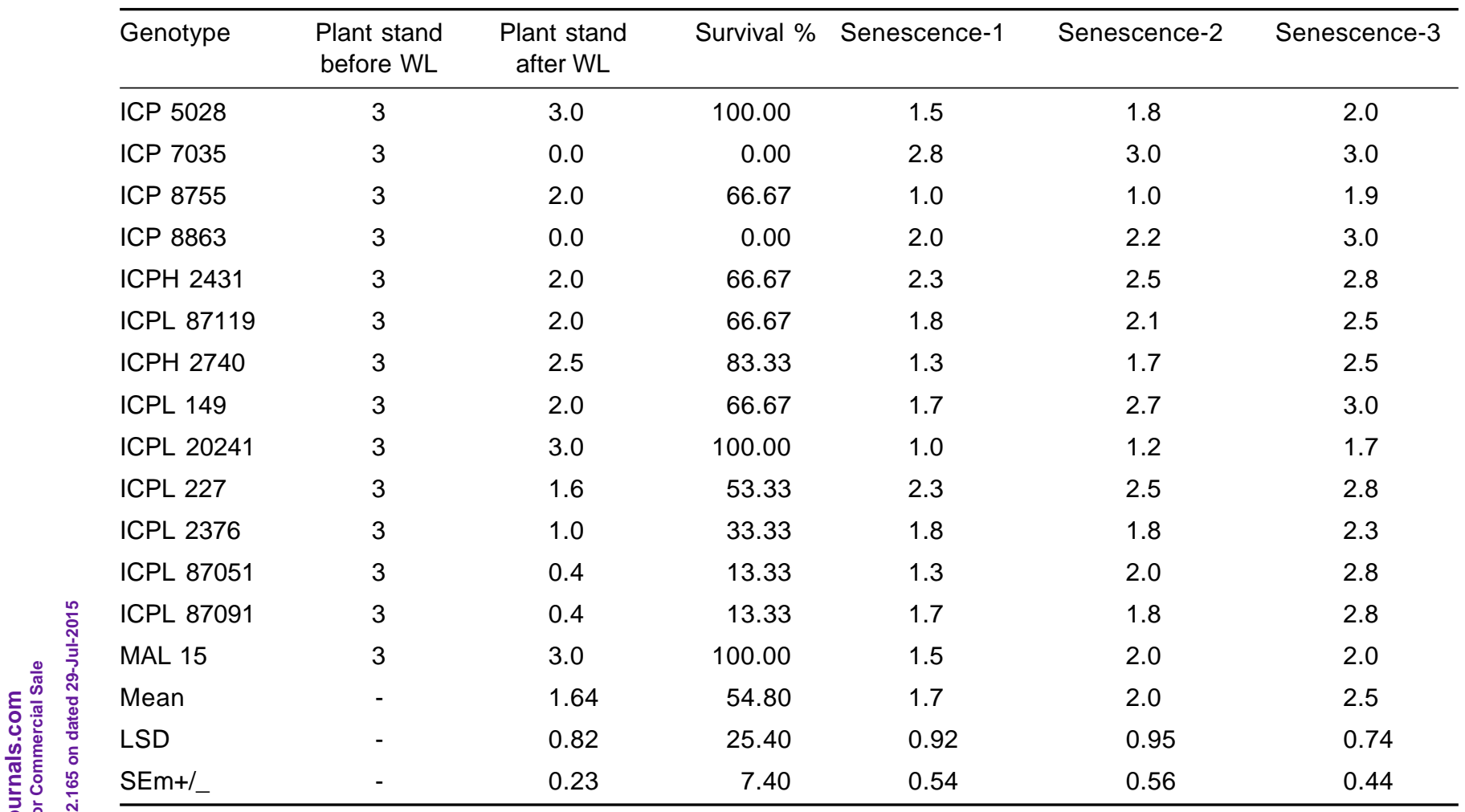

$\mathrm{WL}=$ Water logging

logging conditions exhibit symptoms of leaf senescence, whole plant wilting and epinasty followed by a rapid decline or even its termination. The reductions in survival rate under prolonged submergence has been primarily attributed to anoxia/ hypoxia (Orchard and Jessop 1984). A similar situation was observed in the susceptible genotypes during the present experiment. The observations recorded in this experiments and those reported earlier indicated that more than one mechanisms may be operating to control water-logging tolerance and hence, further studies are required to understand the tolerance mechanism.

Visual observations on the development of lenticels and adventitious roots were recorded on day 8, 16 and 24 after imposing the water-logging treatment. Interestingly among the seven tolerant genotypes, swelling of the stem near root-shoot junction (an indication of lenticels development) was observed only in ICP 5028 and MAL15 after 8 days of treatment and prominent lenticels in the form of cracks in the epidermal layer of the stem tissue were observed on day 16 (Fig. 1A). While, in other tolerant genotypes viz., ICPH 2431, ICPL 87119, ICPH 2740 lenticels were observed on day 24 . On the contrary, in remaining two tolerant genotypes, ICPL20241 and ICPL149 lenticels were absent and instead prominent adventitious roots were developed near the root shoot junction (Fig. 1B). Such adventitious roots were absent in ICP5028 and MAL15. These observations showed that ICP5028 and MAL15 had adapted to water-logging stress early as compared to other surviving genotypes. In the present study, the pigeonpea genotypes adapted to water-logging stress developed attributes such as adventitious roots (in ICPL 20241 and ICPL 149); lenticels (in ICP 5028, ICPH 2431, ICPL 87119, ICPH 2740 and MAL15); and aerenchyma cells in all the seven genotypes. These results are similar to those reported by Pourabdal et al. (2008) in Zea mays, Thomson et al. (1992) and Huang et al. (1994) in wheat, Pires et al. (2002) and Shimamura et al. (2003, 2010) in soybean.

The examination of the transverse sections of the samples showed that ICP 5028 (Fig. 2), MAL15, ICPH 2740, ICPL 149 and other surviving genotypes had developed aerenchyma cells, while these cells were absent in the susceptible genotypes ICP7035 (Fig. 3), ICP 8755, ICP 8863, ICPL 2376,ICPL 87051 and ICPL 87091. The aerenchyma formation was 


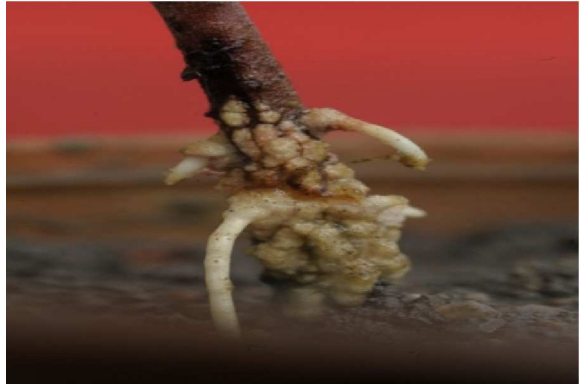

(A)

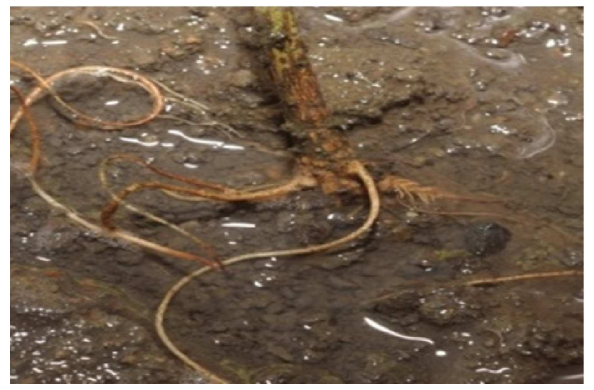

(B)
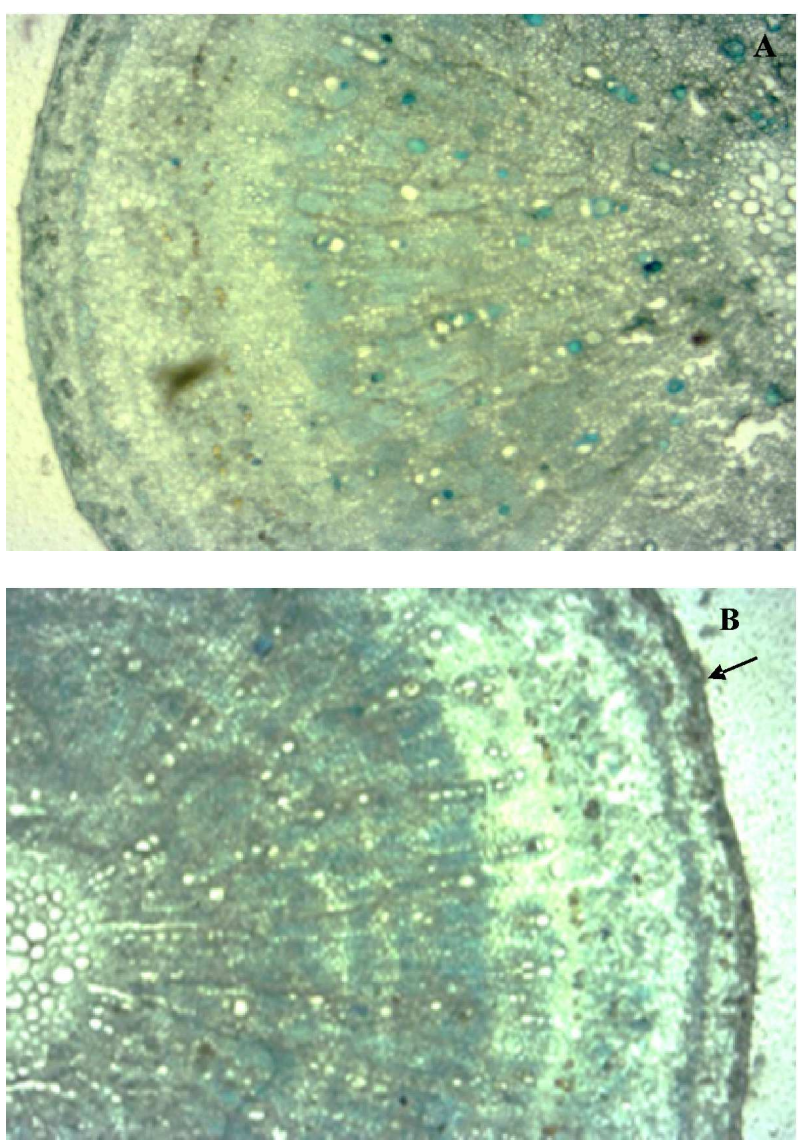

Fig. 3. $A$ = ICP 7035 control (8 days sample) showing normal stem tissue (10X micrograph) B = ICP 7035 susceptible (16 day sample) genotype showing the damaged outer layer of the tissue (10X micrograph)

observed in the whole tissue starting from cortex to medulla or pith of the tissue containing internal gasfilled spaces. These tissue structures appeared like a disorganized 'spoke wheel'. It was also observed that the airspaces in the tissues of these lines increased gradually in size in the second and third sampling (Fig. 4). Shimamura et al. (2003) pointed out that the aerenchyma tissues originate from the external part of the inter-fasicular cambium. Nevertheless, some authors consider the inter-fascicular tissue as the pericycle itself (Angyallossy-Alfonso and Marcati 2003). These aerenchymous tissues had large intercellular spaces and consisted of living cells whose walls failed to be suberized; whereas phloem did not exhibit any intercellular spaces and consisted of dead cells whose walls became suberized, thus disrupting the suppy of vital elements to the plant.

In the tolerant genotypes ICP 5028 and ICPL 20241, the lenticels (white spongy tissue) came out 


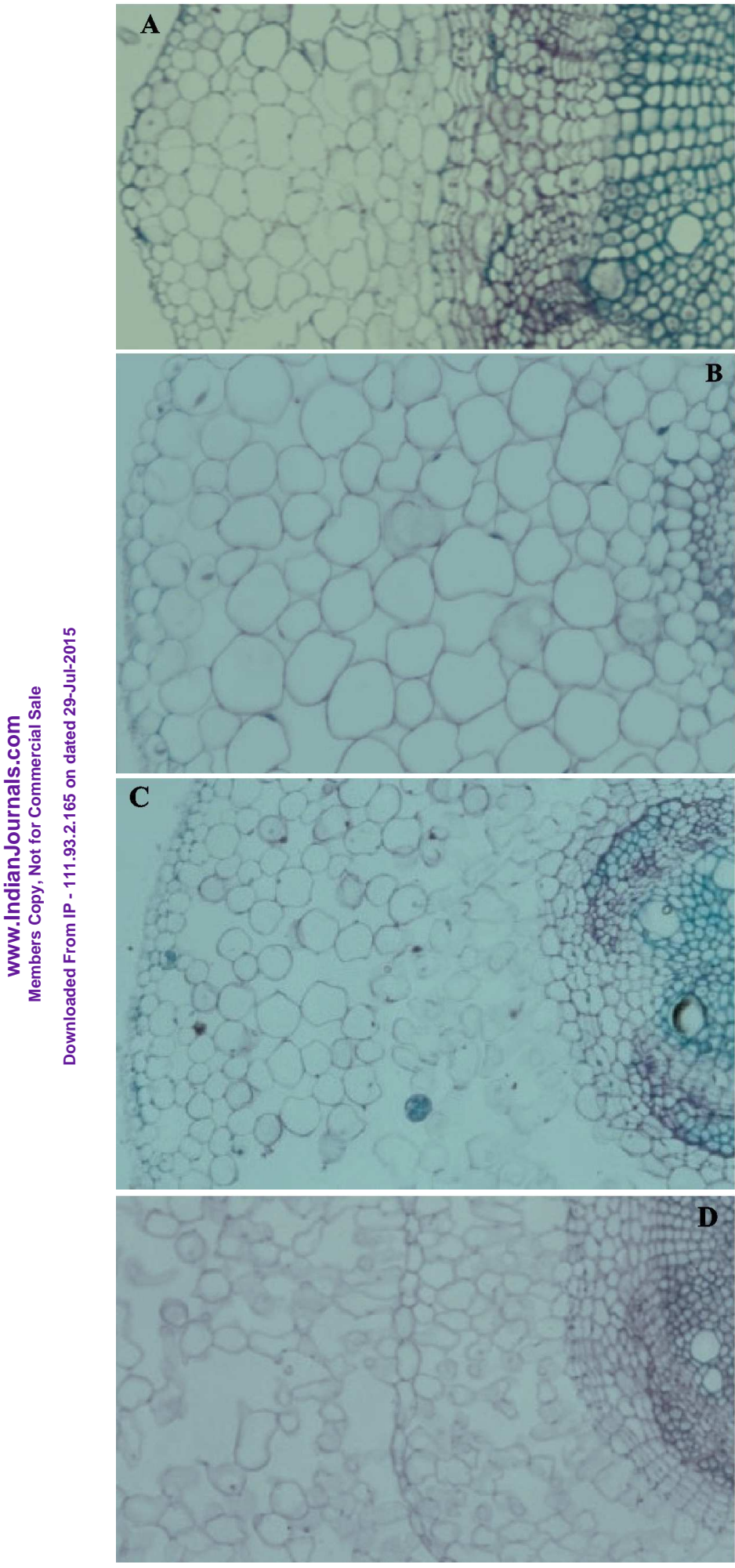

Fig. 4. Transverse sections showing the time-course of aerenchyma formation in ICP 5028 during flooding. Sections were taken $1 \mathrm{~cm}$ from the root-shoot junction: $A=$ control; $B=$ after $8 \mathrm{~d}$ of flooding; $C=$ after $16 \mathrm{~d}$ of flooding and $D=$ after $24 \mathrm{~d}$ of flooding. (40X crop micrograph) by breaking the epidermal layer. It formed a void in the outer part of the stem that facilitated entry of oxygen in aerenchyma and imparted tolerance to waterlogging. The formation of lenticels at the stem-base of tolerant genotypes was also observed visually, and this was in accordance with the findings of Shimamura et al. (2002) reporting formation of hypertrophic lenticels and development of aerenchyma in soybean, which enabled oxygen supply to roots and root nodules in the flooded soils. The sensetive genotypes ICP 7035 and ICP 8863 wilted due to waterlogging stress and no aerenchyma cells were observed and instead the degenerated or damaged cells with blackening of the tissues were observed under the transverse section hence, it may be inferred that aerenchyma cells were primarily responsible for imparting tolerance to water-logging in pigeonpea.

According to Pourabdal et al. (2008) the growth that appears as swelling at the area between base of the stem and roots have a transitional role in carrying oxygen from shoots to roots. Further, these changes depend on the radial cell division and their expansion which is accompanied with the cell collapse and aerenchyma formation. This is an important adaptive mechanism that helps in the diffusion of air from shoot to roots (Visser and Voesenek 2004). Although, the actual physiological role of lenticels is still unclear, their presence is often linked to water-logging tolerance in plants. Adventitious roots replace the basal roots and it is also considered a potential morphological adaptation by plants under water-logging stress (Malik et al. 2001). These specialized roots maintain the continuous supply of water and minerals when the basal root system fails to do so (Mergemann and Santor 2000; Steffens et al. 2006). Similar situation was observed when some interspecific derivatives involving wild Cajanus species $C$. acutifolius, was waterlogged (Mallikarjuna N., unpublished data).

From the above discussion, it can be concluded that tolerance to water-logging stress in pigeonpea may be due to more than one factors and these include maturity duration, seed colour and presence of morphphysiological traits like lenticels, aerenchyma cells and adventitious roots. One of these traits individually or in combination may be responsible for imparting tolerance to water-logging stress. For example, ICPH 2431 and ICPL 149 are early maturing genotypes but were found tolerant to water-logging stress, this may be due to the presence of aerenchyma cells that enable survival under stress. At the same time ICP 7035 and ICP 8755 are late maturing but were found 
Table 2. Morpho-physiological traits of pigeonpea genotypes with their water-logging reaction

\begin{tabular}{lcccllc}
\hline Genotype & $\begin{array}{c}\text { Aerenchyma } \\
\text { cells }\end{array}$ & $\begin{array}{c}\text { Adventitious } \\
\text { roots }\end{array}$ & Lenticels & Maturity & $\begin{array}{l}\text { Seed coat } \\
\text { colour }\end{array}$ & $\begin{array}{c}\text { Reaction to } \\
\text { water-logging }\end{array}$ \\
\hline ICP 5028 & + & - & + & Late & Dark purple & T \\
ICP 7035 & - & - & - & Late & Reddish brown & $\mathrm{S}$ \\
ICP 8755 & - & - & - & Late & Reddish brown & $\mathrm{S}$ \\
ICP 8863 & - & - & - & Early Medium & Orange & $\mathrm{S}$ \\
ICPH 2431 & + & - & + & Early & Brown & $\mathrm{T}$ \\
ICPL 87119 & + & - & + & Medium & Brown & $\mathrm{T}$ \\
ICPH 2740 & + & - & + & Medium & Brown & $\mathrm{T}$ \\
ICPL 149 & + & + & - & Early & Brown & $\mathrm{T}$ \\
ICPL 20241 & + & + & - & Medium & Brown & $\mathrm{T}$ \\
ICPL 227 & - & - & - & Medium & Brown & $\mathrm{S}$ \\
ICP 2376 & - & - & - & Early-Medium & White & $\mathrm{S}$ \\
ICPL 87051 & - & - & - & Medium & White & $\mathrm{S}$ \\
ICPL 87091 & - & - & - & Early & White & $\mathrm{S}$ \\
MAL 15 & + & - & + & Late & Brown & $\mathrm{T}$ \\
\hline
\end{tabular}

+ = Present; - = Absent; T=Tolerant and S=Susceptible

sensitive to water-logging stress which this may be due to absence of morph-physiological traits like aerenchyma cells, lenticels and adventitious roots. Ahmed et al. (2013) discussed about mechanism of water-logging tolerance in plants and revealed that plant which can withstand water-logging condition have mechanisms such as increased availability of soluble sugar, aerenchyma formation, development of adventitious roots, greater activity of glycolytic pathway and fermentation enzymes, and involvement of antioxidant defense mechanism to cope with the oxidative stress induced by waterlogging. Ethylene plays an important role in change of mechanisms of plants in deficiency of oxygen. It was also reported that ethylene induces the genes of enzymes associated with aerenchyma formation, glycolysis and fermentation pathway (Mergemann and Santer 2000).

\section{Breeding strategy}

Results of the present study have shown the presence of three parameters involved in imparting tolerance to water-logging stress in pigeonpea. These include formation of aerenchyma cells, lenticels and adventitious roots. This information is similar to those recorded in other cereal and legume crops. Since this is the first such study in pigeonpea, information on the relative contribution of each parameter and their genetic control is not available. Therefore, pending such information, the breeding efforts to enhance the level of water-logging tolerance should be directed to incorporate all the three parameters into one genotype using traditional breeding approaches. The first approach that could be taken up could be to make a 7-parent diallel and evaluate single cross $F_{1} s$ to study the genetic parameters of the traits involved in the water-logging tolerance and simultaneously, select inbred genotypes with high productivity and enhanced levels of water-logging tolerance. In the present list of tolerant genotypes ICPL 87119 and ICPL 20241 are known for their high productivity. Both the lines produce aerenchyma but ICPL 87119 produces lenticels and ICPL 20241 produces adventitious roots. From such crosses inbred lines that combine all the three traits can be selected easily. Alternatively, a simple backcross program involving the parents with complementary traits can be undertaken and inbred lines that incorporate all the three adaptive traits can be selected.

\section{Acknowledgement}

Authors acknowledge the suggestions given by $\mathrm{Dr} \mathrm{L}$ Krishnamurthy to undertake this research work. The technical support of Ms Hamsaveni Sheri in this study is also acknowledged. 


\section{References}

Ahmed F., Rafii M. Y., Ismail, M. R., Juraimi A. S., Rahim H. A., Asfaliza R. and Latif M. A. 2013. Waterlogging Tolerance of Crops: Breeding, Mechanism of Tolerance, Molecular Approaches, and Future Prospects. BioMed Research International. Volume 2013, Article ID 963525, 10 pages

Angyalossy-Alfonso V. and Marcati C. R. 2003. Cambio vascular. In: Appezzato-da-Gloria B., CarmelloGuerreiro S. M. (eds.). Anatomia vegetal. Editora UFV, Viscosa, Brazil, 207.

Armstrong W. 1979. Aeration in higher plants. Advances in Botanical Research, 7: 225-332.

FAO. (2010). www.faostat.org.

Gunawardena A., Pearce D. M., Jackson M. B., Hawes C. R. and Evans D. E. 2001a.Characterization of programmed cell death during aerenchyma formation induced by ethylene or hypoxia in roots of maize (Zea mays L.). Planta, 212: 205-214.

Gunawardena A., Pearce D. M., Jackson M. B., Hawes C. R. and Evans D. E. 2001b. Rapid changes in cell wall pectic polysaccharides are closely associated with early stages of aerenchyma formation, a spatially localized form of programmed cell death in roots of maize (Zea mays L.) promoted by ethylene. Plant, Cell Environ., 24: 1369-1375.

Hou F. F. and Thseng F. S. 1991. Studies on the flooding tolerance of soybean seed: varietal differences. Euphytica, 57: 169-173.

Huang B., Johnson J. W., Nesmith D. S. and Bridges D. C. 1994. Root and shoot growth of wheat genotypes in response to hypoxia and subsequent resumption of aeration. Crop Sci., 34: 1538-1544.

Khare D., Rao S., Lakhani J. P. and Satpute R. G. 2002. Tolerance for flooding during germination in pigeonpea. Seed Res., 30: 82-87.

Malik A. I., Colmer T. D., Lambers H. and Schortemeyer M. 2001. Changes in physiological and morphological traits of roots and shoots of wheat in response to different depths of waterlogging. Aust. J. Plant Physiol., 28: 1121-1131.

Marschner H. 1995. Mineral Nutrition of Higher Plants. Second edition. London, Academic Press Limited: 889 str.

Mergemann H. and Santer M. 2000. Ethylene induces epidermal cell death at the site of adventitious root emergence in rice. Plant Physiol., 124: 609-614.

Orchard P. W. and Jessop R. S. 1984. The response of sorghum and sunflower to short term waterlogging. I. Effects of stage of development and duration of waterlogging on growth and yield. Plant Soil, 81: 119-132.

Pires J. L. F., Soprano E. and Cassol B. 2002.
Morphophysiological changes of soybean in flooded soils. Pesquisa Agropecuaria Brasileira, 37: 41-50.

Ponnamperuma F. N. 1984. Effects of flooding on soils. In Flooding and Plant Growth. T. T. Kozlowski (ed.), Academic Press, Orlando, FL, pp. 9-45.

Pourabdal L., Heidary R. and Farboodnia T. 2008. Effects of Different Flooding periods on Some Histochemicals of Zea mays L. Seedlings. Plant Sci. Res., 1(1): 8-12.

Shimamura S., Mochizuki T., Nada Y. and Fukuyama M. 2002. Secondary aerenchyma formation and its relation to nitrogen fixation in root nodules of soybean plants (Glycine max) grown under flooded conditions. Plant Prod. Sci., 5: 294-300.

Shimamura S., Mochizuki T., Nada Y. and Fukuyama M. 2003. Formation and function of secondary aerenchyma in hypocotyl, roots and nodules of soybean (Glycine max) under flooded conditions. Plant Soil, 251: 351-359.

Shimamura S., Yamamoto R., Nakamura T., Shimada S. and Komatsu S. 2010. Stem hypertrophic lenticels and secondary aerenchyma enable oxygen transport to roots of soybean in flooded soil. Ann. Bot., 106: 277-284.

Singh K., Sharma S. P., Singh T. K. and Singh Y. 1986. Effect of waterlogging on growth, yield and nutrient concentration of black gram and green gram under subtropical condition of Varanasi. Ann. Agr. Res., 7: 169-177.

Steffens B., Wang J. and Sauter M. 2006. Interactions between ethylene, gibberellin and abscisic acid regulate emergence and growth rate of adventitious roots in deep water rice. Planta, 223: 604-612.

Sultana R., Vales M. I., Saxena K. B., Rathore A., Rao S., Rao S. K., Mula M. G. and Kumar R. V. 2012. Waterlogging tolerance in pigeonpea (Cajanus cajan (L.) Millsp.): genotypic variability and identification of tolerant genotypes. J. Agril. Sci., pp. 1-14. ISSN 1469-5146.

Takele A. and Mcdavid C. R. 1995. The response of pigeonpea cultivars to short durations of waterlogging. African Crop Sci. J., 3(1): 51-58.

Thomson C. J., Colmer T. D., Watkin E. L. J. and Greenway H. 1992. Tolerance of wheat (Triticum aestivum cvs. Gamenya and Kite) and triticale (Triticosecale cv. Muir) to waterlogging. New Phytol., 120: 335-344.

Visser E. J. W. and Voesenek L. A. C. J. 2004. Acclimation to soil flooding - sensing and signal - transduction. Plant Soil, 254: 197-214.

Zaidi P. H., Maniselvan P., Yadav P., Singh A. K., Sultana R., Dureja P., Singh R. P. and Srinivasan G. 2007. Stress-adaptive changes in tropical maize (Zea mays L.) under excessive soil moisture stress. Maydica, 52: $159-171$. 